\title{
The Effect of Specific Antiserum on the Resistance of Neisseria gonorrhoeae to Intracellular Killing by Phagocytes of Human Blood
}

\author{
By D. R. VEALE, C. W. PENN, S. SUTTON AND H. SMITH \\ Department of Microbiology, University of Birmingham, Birmingham B15 2TT
}

(Received 6 December 1977)

\begin{abstract}
The high natural resistance of gonococci showing a characteristic 'double highlight' (DH) colonial morphology (Penn, Veale \& Smith, 1977b) to intracellular killing by human phagocytes was markedly reduced by addition of rabbit antiserum to the phagocytosis medium or by preincubation of organisms with antiserum. Antisera raised to three different DH gonococcal strains showed a complex pattern of specificity in phagocytosis tests with the homologous organisms and three other DH strains. The effect of antiserum could be neutralized by adsorption with intact organisms or with extracts, prepared ultrasonically, of the homologous strain. Antiserum also promoted the intracellular killing of a strain which had a 'single highlight' colonial morphology (Penn et al., 1977 b) and a low natural resistance to phagocytic killing, but adsorption with this strain neutralized the antiserum less consistently than the DH strain. The neutralization of antiserum-mediated promotion of intracellular killing by extracts of organisms naturally resistant to such killing may provide an assay for the aggressins responsible for this resistance.
\end{abstract}

\section{INTRODUCTION}

The observation of apparently healthy intracellular gonococci in electron micrographs of polymorphonuclear (PMN) phagocytes from urethral pus (Novotny, Short \& Walker, 1975; Ovchinnikov, Delektorskij \& Dmitriev, 1976; Ovchinnikov \& Delektorskij, 1977) suggests that some gonococci are capable of surviving in these cells even though others are undoubtedly killed. In support of this, Veale et al. (1976) reported that some members of a small colony-forming pilated strain (Bs) of gonococci grown in vitro survived and multiplied inside human buffy coat phagocytes (mainly PMN) for at least $15 \mathrm{~h}$. Furthermore, strain BS organisms adapted to growth in vivo (strain BS5) by passage through subcutaneous chambers implanted into guinea pigs (Veale et al., 1975) and which resembled urethral pus organisms in some respects (Penn et al., 1976) were more resistant to intracellular killing during the first hour of incubation with phagocytes than were the parent strain organisms (Witt et al., 1976a). Subsequently, strain BS was shown to contain at least two different types of organisms. The majority, designated BSSH, formed colonies which exhibited a 'single highlight' (SH) morphology when examined under the lighting conditions described by Penn, Veale \& Smith (1977b). The others, designated BSDH, formed colonies with a 'double highlight' $(\mathrm{DH})$ morphology like that of the organisms adapted to growth in guinea-pig chambers. Strain BSDH was more pilated and more infective for guinea-pig chambers than strain BSSH (Penn et al., 1977b). Whereas the resistance of strain BSSH to intracellular phagocytic killing was similar to that of the parent strain (BS), the resistance of strain BSDH was greater and similar to that of the guinea-pig adapted strain BS5, indicating that in vivo growth had selected organisms with a high resistance to intracellular killing.

The fractionation and identification of the aggressin(s) responsible for resistance to 
intracellular killing requires an assay for the aggressin in extracts of BSDH or similarly resistant organisms. The simplest assay would be the direct promotion of resistance to intracellular killing of a susceptible organism (such as strain BSSH) by adding the extract to phagocytosis tests. An indirect assay would be possible if antibody abolished the resistance of gonococci to killing by phagocytes and this resistance was restored by treatment of antiserum with extracts of resistant organisms. This paper describes investigations into the feasibility of the latter approach and the type specificity of antibody activity.

\section{METHODS}

Strains of gonococci. All parent strains were obtained from human urethral pus. Strains BSDH and BSSH were derived from strain BS, and strains ASDH, CSDH, DSDH, ESDH and FSDH from strains AS, CS, DS, ES and FS (Veale et al., 1975; Penn et al., 1977a,b). They were stored, cultured and counted as described before (Veale et al., 1975; Penn et al., 1976).

Extracts of strain BSDH. Strain BSDH was grown on AG medium (Penn et al., 1976) and extracted as follows: (i) $2 \times 10^{10}$ to $2 \times 10^{11}$ gonococci $\mathrm{ml}^{-1}$ were extracted in Trypticase Soy Broth (TSB; BBL) by vortex mixing with glass beads (Penn et al., 1976); (ii) $3 \times 10^{10}$ gonococci $\mathrm{ml}^{-1}$ were extracted in lithium acetate/EDTA buffer by vigorous shaking for $2 \mathrm{~h}$ at $45^{\circ} \mathrm{C}$ (Johnston, Holmes \& Gotschlich, 1976) followed by overnight dialysis at $4{ }^{\circ} \mathrm{C}$ against phosphate-buffered saline (PBS, pH 7.2; Penn et al., 1976); and (iii) $5 \times 10^{10}$ gonococci $\mathrm{ml}^{-1}$ in PBS (1 to $5 \mathrm{ml}$ ) were ultrasonically disrupted (Rapidis 180 generator, Ultrasonics Ltd; $3 \mathrm{~mm}$ diam. probe, $20 \mathrm{kHz}, 72 \mathrm{~W}, 6 \mathrm{~min}$ at $\left.0^{\circ} \mathrm{C}\right)$. Extracts were centrifuged $(2000 \mathrm{~g}, 15$ to $30 \mathrm{~min}$, room temperature) and sterilized by membrane filtration $(0.22 \mu \mathrm{m}$ pore size). These extracts were not detectably bactericidal for gonococci.

Human phagocytes. Populations of phagocytes consisting predominantly (about $80 \%$ of PMN phagocytes were obtained from fresh human peripheral blood as described by Witt, Veale \& Smith (1976b).

Test for resistance to intracellular killing by human phagocytes. The modification of Penn et al. $(1977 \mathrm{~b})$ of the test described by Witt et al. $(1976 a, b)$ was used. Gonococci $\left(2 \times 10^{7}\right.$ organisms ml $\left.{ }^{-1}\right)$ were conditioned $\left(1 \mathrm{~h}\right.$ at $\left.37^{\circ} \mathrm{C}\right)$ in the phagocytosis medium before mixing with the phagocytes. The ratio of phagocytes to the total gonococcal inoculum was 1:1 and the phagocytosis time was $1 \mathrm{~h}$ unless otherwise stated. One hour after mixing the bacteria and cells and allowing them to settle in Leighton tubes, microscopic and viable counts were made on the infected phagocyte deposits. Results are expressed as: (i) the number of gonococci per phagocyte seen visually and (ii) viable cell-associated gonococci as a percentage of the total microscopic count (Penn et al., 1977b; Table 3). However, in the calculation of the latter, which is a measure of the resistance to intracellular killing, the viable counts of deposited gonococci on the surface of control tubes (a measure of the settled, non-cell-associated gonococci) were subtracted from the viable counts of the infected phagocyte deposits. In most experiments, the counts in control tubes were not more than $10 \%$ of those in tubes containing infected phagocytes (without added antiserum) and never more than $20 \%$ for any of the results quoted. Electron microscopy of phagocytes and associated gonococci was as described by Witt et al. (1976a) after interaction at a 1:100 ratio of phagocytes to gonococci.

Antisera. Unless otherwise stated, these were raised in rabbits by multiple intravenous injections of live gonococci in TSB. The following antisera were used: (i) antiserum (anti-BS) to the parent BS strain (which contained both BSDH and BSSH organisms) was raised by injection of increasing graded doses of $1 \times 10^{7}$ to $1 \times 10^{9}$ organisms (i.v.) on days $1,3,17,24,29$, and of $5 \times 10^{8}$ to $1 \times 10^{9}$ organisms (i.m. in Freund's incomplete adjuvant) on days 44, 127, 143 and 194 with bleeding on day 200; (ii) antisera to the DH strains were raised by i.v. injection of increasing graded doses of $5 \times 10^{7}$ to $5 \times 10^{8}$ organisms on days $0,4,7,11$ and 14 with bleeding on days 22 and 27; (iii) hyperimmune antisera to the DH strains were raised as in (ii) with additional inoculations on days $35,49,54$ and 59 with bleeding on days 88 and 89 . All antisera were sterilized by membrane filtration $\left(0.22 \mu \mathrm{m}\right.$ pore size), heated at $56^{\circ} \mathrm{C}$ for $1 \mathrm{~h}$ and stored at $-20^{\circ} \mathrm{C}$. In phagocytosis medium alone these antisera were not bactericidal for gonococci.

Adsorption of anti-BS-serum. The antiserum was mixed (overnight at $4{ }^{\circ} \mathrm{C}$ ) with: (i) whole gonococci (about $5 \times 10^{10} \mathrm{ml}^{-1}$ in undiluted antiserum) grown on AG agar and then removed by centrifugation (15 min, $2000 \mathrm{~g}$, room temperature); or (ii) an equal volume of one of the three types of "extracts of DH organisms described above.

Treatment of gonococci with antisera for phagocytosis tests. In some experiments antiserum was present throughout the test; in others the gonococci were pretreated with antiserum. In the former, antiserum was added to the gonococci in phagocytosis medium immediately after the conditioning period (Witt et al., $1976 \mathrm{~b}$ ) and before incubation with phagocytes. After preliminary experiments, antisera were added to give a concentration in the test $[1 \%(\mathrm{v} / \mathrm{v})$ for anti-Bs serum and the hyperimmune sera; $5 \%(\mathrm{v} / \mathrm{v})$ for the others] 
Table 1. Effect of antiserum on resistance of strain $\mathrm{BSDH}$ to intracellular killing by human phagocytes; viable and microscopic counts of strain $\mathrm{BSDH} 1 \mathrm{~h}$ after mixing with phagocytes

For methods, see Penn el al. $(1977 b)$ and Witt et al. $(1976 a, b)$. Phagocytes $\left(10^{6}\right.$; about $80 \%$ PMN phagocytes) were added to each Leighton tube. Counts were done on cells deposited on the flat surface.

$\begin{array}{ccccc}\begin{array}{c}\text { Expt and } \\ \text { blood donor }\end{array} & \begin{array}{c}\text { Inoculum: } \\ 10^{-4} \times \text { viable } \\ \text { count }\end{array} & \text { Antiserum* } & \begin{array}{c}\text { Deposit: } \\ \text { gonococci per } \\ \text { phagocyte } \dagger\end{array} & \begin{array}{c}\text { gonococci as } \% \\ \text { of total } \\ \text { microscopic } \\ \text { count } \ddagger\end{array} \\ \text { 1. NP } & 22 & - & 0.46 & 81 \\ \text { 2. CP } & 22 & + & 0.22 & <1.0 \\ & 150 & - & 0.63 & 35 \\ \text { 3. NP } & 150 & + & 0.18 & <1.0 \\ & 53 & - & 0.66 & 15 \\ \text { 4. MR } & 93 & + & 1.0 & 4.5 \\ & 28 & - & 0.58 & 46 \\ & 38 & + & 1.4 & 9.7\end{array}$

* Antiserum to strain BS (a mixture of BSDH and BSSH organisms; see Methods) was added to the phagocytosis medium $(1 \%, v / v)$ in experiments 1 and 2 . In experiments 3 and 4 , organisms were preincubated with antiserum which was then removed by washing (see Methods) and viable counts of the untreated and antibody-treated inoculum were determined.

$\dagger$ From visual counts on at least 100 infected and uninfected cells. Electron microscopy showed that most ( $>90 \%$ ) of these organisms would be intracellular.

\$ Viable phagocyte-associated gonococci obtained by subtracting deposit count in control tubes without phagocytes from that in tubes with phagocytes. Total microscopic count obtained by multiplying average number of phagocytes per tube by the average number of gonococci per phagocyte.

which produced similar reductions in the resistance of homologous strains. When $5 \%(\mathrm{v} / \mathrm{v})$ antisera was added, a corresponding reduction was made in the amount of human serum in the phagocytosis medium (Witt et al., 1976a,b). Antisera adsorbed with gonococcal extracts $(1: 1)$ were used at the appropriate concentration. Pretreatment of gonococci with antiserum $(2 \%, \mathrm{v} / \mathrm{v})$ was carried out during the $1 \mathrm{~h}$ conditioning period; antiserum was then removed by washing with medium followed by centrifuging ( $2000 \mathrm{~g}$, 10 to $15 \mathrm{~min}, 4$ to $10^{\circ} \mathrm{C}$ ) three times. The organisms were suspended in fresh medium before mixing with phagocytes. Control organisms (without added antiserum) were treated similarly and, after the final washing, were either suspended in fresh medium or in the supernatant from the third wash with medium of the antiserum-treated gonococci.

\section{RESULTS}

\section{Effect of antiserum on the resistance of strain $\mathrm{BSDH}$ to intracellular killing by human phagocytes}

Viable and microscopic counts of cell-associated gonococci were determined $1 \mathrm{~h}$ after mixing bacteria with phagocytes and allowing them to settle on the surface of Leighton tubes (Table 1). Experiments 1 and 2 are representative of 18 experiments in which the anti-BS serum remained in the phagocytosis medium throughout the test. In most experiments, the presence of antiserum significantly $(P<0.01)$ reduced the number of gonococci seen associated with the phagocytes (mean for 18 experiments; 0.42 gonococci per phagocyte) compared with untreated tubes ( 1.06 gonococci per phagocyte). Antiserum also reduced the resistance of gonococci to intracellular killing as shown by the gross reduction $(>70 \%$ in $14 / 18$ experiments and 50 to $70 \%$ in $3 / 18$ experiments) of viable gonococci associated with the phagocytes expressed as a percentage of the total number of cell-associated gonococci estimated from microscopic counts. Experiments 3 and 4 are representative of 12 experiments where gonococci were pretreated with anti-BS serum (followed by washing to remove unbound antiserum) before mixing with the phagocytes. This treatment also 
Table 2. Effect of rabbit antiserum on the ingestion and intracellular killing of strain BSDH by human phagocytes after different periods of incubation

For methods, see Penn et al. $(1977 b)$, Witt et al. $(1976 a, b)$ and Table 1. Similar results were obtained in two other experiments.

\begin{tabular}{|c|c|c|c|c|}
\hline $\begin{array}{l}\text { Inoculum: } \\
10^{-6} \times \text { viable } \\
\text { count }\end{array}$ & Antiserum* & $\begin{array}{l}\text { Incubation } \\
\text { time (min) }\end{array}$ & $\begin{array}{c}\text { Deposit: } \\
\text { gonococci per } \\
\text { phagocyte } \dagger\end{array}$ & $\begin{array}{l}\text { Deposit: } \\
\text { viable } \\
\text { phagocyte- } \\
\text { associated } \\
\text { gonococci as } \\
\% \text { of total } \\
\text { microscopic } \\
\text { count } \ddagger\end{array}$ \\
\hline 480 & - & $\begin{array}{r}5 \\
15 \\
30 \\
60\end{array}$ & $\begin{array}{l}0 \cdot 23 \\
0 \cdot 37 \\
0 \cdot 42 \\
0 \cdot 46\end{array}$ & $\begin{array}{l}57 \\
31 \\
38 \\
57\end{array}$ \\
\hline 480 & + & $\begin{array}{r}5 \\
15 \\
30 \\
60\end{array}$ & $\begin{array}{l}0.20 \\
0 \cdot 14 \\
0 \cdot 34 \\
0 \cdot 47\end{array}$ & $\begin{array}{c}11 \\
14 \\
2 \cdot 4 \\
15\end{array}$ \\
\hline
\end{tabular}

* Hyperimmune antiserum to strain BSDH was added to the phagocytosis medium $(5 \%, \mathrm{v} / \mathrm{v})$.

$\dagger$ From visual counts on 200 to 400 infected and uninfected cells.

\$ See Table 1 .

reduced the resistance of strain BSDH to intracellular killing ( $>70 \%$ in $10 / 12$ experiments and 50 to $70 \%$ in $1 / 12$ experiments). In the majority of these experiments the number of gonococci seen associated with phagocytes was increased after treatment with antiserum but this was not statistically significant.

In three experiments the effect of hyperimmune antiserum to strain BSDH on the resistance of strain BSDH to intracellular killing was observed after 5, 15, 30 and 60 min incubation. The results of one experiment are shown in Table 2. A ratio of 100 gonococci to 1 phagocyte was used instead of the 1:1 ratio employed in the experiments detailed in Table 1 so that ingestion could be measured after short incubation times. The number of organisms seen associated with phagocytes increased with the length of incubation and in two experiments addition of antiserum made little difference to the microscopic counts. In a third experiment, antiserum increased the number of gonococci seen associated with phagocytes but the ratio of numbers in serum-treated tubes to those in untreated tubes did not vary greatly with time. In all three experiments, antiserum reduced the resistance of gonococci to intracellular killing by phagocytes after 5 or more min incubation.

In two experiments, the resistance of strain BSSH, which was lower than that of strain BSDH in the absence of antiserum (Penn et al., 1977b), was further reduced by the addition of antiserum to strain BS.

\section{Specificity of antiserum-mediated reduction of the resistance of six gonococcal strains to intracellular killing by human phagocytes}

The action of various antisera on the resistance of six DH strains to intracellular killing by human phagocytes is shown in Table 3. Anti-Bs serum reduced the resistance of strains ASDH and BSDH but not CSDH indicating a degree of strain specificity. The pattern of strain specificity shown by antisera raised to $\mathrm{DH}$ strains was complex. Antisera from the initial bleeds were used at a fivefold higher concentration than the hyperimmune antisera to give comparable activity, but in most cases they showed similar patterns of type specificity. Gonococcal strains ASDH and CSDH were consistently affected by anti-BSDH and anti-CSDH serum respectively and occasionally by anti-ESDH serum. The resistance of strain BSDH was affected by anti-BSDH and anti-ESDH but not consistently by anti-CSDH serum. Strain DSDH 
Table 3. Specificity of action of rabbit antisera on the resistance of six DH strains to intracellular killing by human phagocytes

For methods, see Penn et al. $(1977 b)$, Witt et al. $(1976 a, b)$ and Table 1.

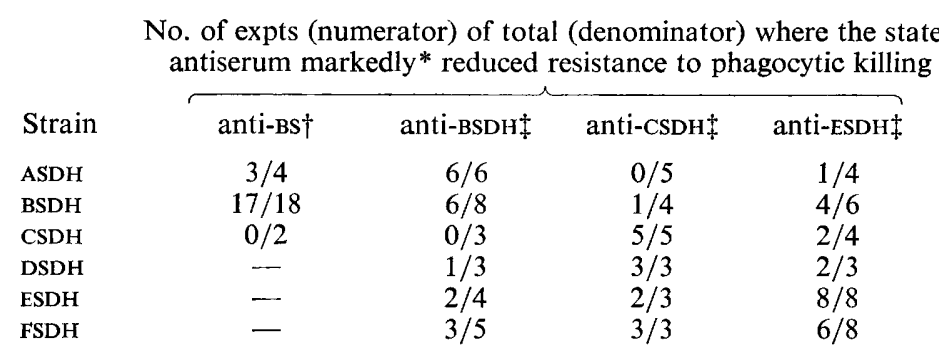

* The arbitrarily fixed level of reduction was as follows: after $1 \mathrm{~h}$ incubation the numbers of viable phagocyte-associated gonococci expressed as \% total microscopic count in antiserum-treated tubes were less than half those found in control tubes without antiserum.

$\dagger$ Antiserum to strain BS (a mixture of BSDH and BSSH organisms; see Methods) was added to the phagocytosis medium $(1 \%, \mathrm{v} / \mathrm{v})$.

$\ddagger$ Pooled results for antiserum raised by a short course of inoculations [added to a concentration of $5 \%$ $(\mathrm{v} / \mathrm{v})]$ and hyperimmune serum $(1 \%, \mathrm{v} / \mathrm{v})$.

was affected by anti-CSDH and anti-ESDH and occasionally by anti-BSDH serum. Strains ESDH and FSDH were affected by most sera and in particular by hyperimmune antisera.

\section{Effect of adsorption with whole organisms on the action of anti-BS serum on the resistance of strain $\mathrm{BSDH}$ to intracellular killing by human phagocytes}

Adsorption of anti-BS serum with BSDH organisms consistently neutralized its promotion of intracellular killing (Table 4). In 5/10 experiments (involving six different preparations of adsorbed serum) the resistance of strain BSDH organisms treated with adsorbed serum was similar to that of untreated organisms and in 5/10 experiments there was partial neutralization of the effect of the antiserum. Adsorption with strain BSSH gave variable results: the effect of anti-BS serum was neutralized in $4 / 11$ experiments (involving four different preparations of adsorbed serum), partially neutralized in $2 / 11$ and unaffected in $5 / 11$. Adsorption appeared to be strain specific as in seven experiments there was little or no neutralization of anti-Bs serum by the heterologous strain CSDH (Table 4).

\section{Effect of adsorption with cell-free extracts of strains $\mathrm{BSDH}$ and $\mathrm{CSDH}$ on the action of anti-BS serum on the resistance of strain $\mathrm{BSDH}$ to intracellular killing by human phagocytes}

Extracts of strain BSDH made by washing with TSB neutralized the action of anti-BS serum in only $1 / 4$ experiments and treatment with lithium acetate/EDTA(three experiments) had little or no effect on the action of anti-Bs serum. However, cell-free extracts of strain BSDH prepared ultrasonically partially or completely neutralized the action of the serum in $3 / 4$ experiments (experiments 1 and 2, Table 5 , are representative). In these experiments, the antiserum/sonicate mixtures were present throughout the phagocytosis test but the same result, i.e. neutralization of the effect of antiserum, was achieved with sonicates of strain BSDH in five further experiments in which the antiserum/sonicate mixtures were removed from the treated gonococci before exposure to phagocytes (experiment 3 , Table 5 , is representative). In contrast, in these pretreatment experiments, a sonicate of strain CSDH was unable to neutralize the effect of the antiserum (experiment 3 , Table 5) testifying to the strain-specific effect. However, when the sonicate of strain CSDH was present throughout the test (experiment 2, Table 5), it counteracted the effect of antiserum in neutralizing the natural resistance of strain BSDH to intracellular killing, presumably by direct interference. 
Table 4. Effect of adsorption with intact gonococci on the action of anti-BS serum on the resistance of strain $\mathrm{BSDH}$ to intracellular killing by human phagocytes

For methods, see Penn et al. $(1977 b)$, Witt et al. $(1976 a, b)$ and Table 1.

\begin{tabular}{|c|c|c|c|c|}
\hline $\begin{array}{l}\text { Expt and } \\
\text { blood donor }\end{array}$ & $\begin{array}{c}\text { Inoculum: } \\
10^{-4} \times \text { viable } \\
\text { count }\end{array}$ & Antiserum* & $\begin{array}{l}\text { Adsorbed } \\
\text { with:* }\end{array}$ & $\begin{array}{c}\text { gonococci as } \\
\text { of total } \\
\text { microscopic } \\
\text { count } \uparrow\end{array}$ \\
\hline 1. NP & 160 & $\begin{array}{l}- \\
+ \\
+ \\
+\end{array}$ & $\begin{array}{c}- \\
- \\
\text { BSDH } \\
\text { BSSH }\end{array}$ & $\begin{array}{r}14 \\
<1 \cdot 0 \\
8 \cdot 3 \\
<1 \cdot 0\end{array}$ \\
\hline 2. $\mathrm{DV}$ & 300 & $\begin{array}{l}- \\
+ \\
+ \\
+\end{array}$ & $\begin{array}{c}- \\
- \\
\text { BSDH } \\
\text { BSSH }\end{array}$ & $\begin{array}{c}32 \\
7 \cdot 2 \\
43 \\
3 \cdot 4\end{array}$ \\
\hline 3. $\mathrm{DV}$ & 380 & $\begin{array}{l}- \\
+ \\
+ \\
+\end{array}$ & $\begin{array}{c}- \\
- \\
\text { BSDH } \\
\text { CSDH }\end{array}$ & $\begin{array}{r}12 \\
1 \cdot 1 \\
5 \cdot 7 \\
<1.0\end{array}$ \\
\hline 4. RS & 200 & $\begin{array}{l}- \\
+ \\
+ \\
+\end{array}$ & $\begin{array}{c}- \\
- \\
\text { BSDH } \\
\text { CSDH }\end{array}$ & $\begin{array}{r}100 \\
14 \\
78 \\
21\end{array}$ \\
\hline
\end{tabular}

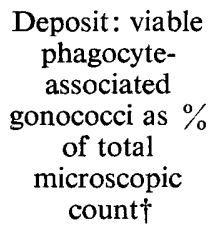

* Antiserum to strain BS (a mixture of BSDH and BSSH organisms; see Methods), either adsorbed or unadsorbed with intact gonococci, was added to the phagocytosis medium $(1 \%, \mathrm{v} / \mathrm{v})$.

$\uparrow$ See Table 1 .

Table 5. Effect of adsorption with ultrasonically prepared extracts of gonococci on the action of anti-BS serum on the resistance of strain $\mathrm{BSDH}$ to intracellular killing by human phagocytes

For methods, see Penn et al. (1977b), Witt et al. $(1976 a, b)$ and Table 1.

\begin{tabular}{|c|c|c|c|c|}
\hline $\begin{array}{l}\text { Expt and } \\
\text { blood donor }\end{array}$ & $\begin{array}{l}\text { Inoculum: } \\
10^{-4} \times \text { viable } \\
\text { count }\end{array}$ & Antiserum* & $\begin{array}{c}\text { Adsorbed } \\
\text { with } \\
\text { sonicate of :* }\end{array}$ & $\begin{array}{l}\text { Deposit: viable } \\
\text { phagocyte- } \\
\text { associated } \\
\text { gonococci as } \% \\
\text { of total } \\
\text { microscopic } \\
\text { count } \dagger\end{array}$ \\
\hline 1. DV & 380 & $\begin{array}{l}- \\
+ \\
+\end{array}$ & $\begin{array}{c}- \\
- \\
\text { BSDH }\end{array}$ & $\begin{array}{c}12 \\
1 \cdot 1 \\
23\end{array}$ \\
\hline 2. RS & 450 & $\begin{array}{l}- \\
+ \\
+ \\
+\end{array}$ & $\begin{array}{c}- \\
- \\
\text { BSDH } \\
\text { CSDH }\end{array}$ & $\begin{array}{c}24 \\
7 \cdot 6 \\
28 \\
24\end{array}$ \\
\hline 3. DV & $\begin{array}{l}36 \\
37 \\
52 \\
93\end{array}$ & $\begin{array}{l}- \\
+ \\
+ \\
+\end{array}$ & $\begin{array}{c}- \\
- \\
\text { BSDH } \\
\text { CSDH }\end{array}$ & $\begin{array}{c}10 \\
3 \cdot 0 \\
16 \\
4 \cdot 5\end{array}$ \\
\hline
\end{tabular}

* Antiserum to strain Bs (a mixture of BSSH and BSDH; see Methods), either adsorbed or unadsorbed with sonicate, was added to the phagocytosis medium $(1 \%, v / v)$, except in experiment 3 where organisms were preincubated with antisera which were then removed by washing.

$\dagger$ See Table 1. 


\section{DISCUSSION}

Rabbit anti-gonococcal sera caused a substantial fall in resistance of gonococci to killing by human phagocytes. Free antiserum was not necessary for reduction of resistance as this could also be achieved by preincubation of the gonococci with antiserum followed by washing. The enhancement of killing was a rapid effect, being noticed within 5 min (Table 2). As all sera were heat inactivated, the mechanism of intracellular killing must differ from that described by Brooks, Israel \& Petersen (1976) which required a heat-labile factor, probably complement. Antiserum against strain BS, which contained BSDH and BSSH organisms, was equally effective in promoting killing of both the naturally resistant organisms (BSDH) and the naturally susceptible organisms (BSSH).

Expecting some opsonic effect of antisera as described by Punsalang \& Sawyer (1973), Ofek, Beachey \& Bisno (1974) and Bisno et al. (1975), we were surprised to find that the number of cell-associated gonococci measured by simple visual counts was often decreased when antiserum was added. These results probably reflect an increase in the rate of intracellular digestion rather than a decrease in the rate of ingestion. In fact, the figures given in the tables may be under-estimates of the enhancement of intracellular killing by antiserum. The complex pattern of strain specificity shown by six DH strains and antisera raised against three of them indicated that both common and strain-specific antigens and antibodies were involved in antiserum-mediated loss of resistance to intracellular killing. Some strains were more susceptible to loss of resistance mediated by heterologous antisera than others. Penn et al. $(1977 a, 1978)$ have shown three immunotypes in six strains grown in guinea-pig chambers (and derived from the same parent strains as those used in this study) as judged by active immunity to infection of plastic chambers implanted subcutaneously in guinea pigs. These immunotypes were related to the bactericidal action of serum raised in guinea pigs by live chamber infection and to type-specific antigens demonstrable by two-dimensional immunoelectrophoresis against rabbit antisera. Clearly, this simple relation between the types does not hold for the neutralization of resistance to killing by phagocytes (Table 3) indicating that different antigens may be involved. At present, it is unknown if any of the antigens responsible for the above biological effect are related to other strain-specific antigens that have been described such as pili (Buchanan, 1975; Novotny \& Turner, 1975) and outer membrane proteins (Johnston et al., 1976).

The resistance-reducing effect of homologous antisera could be neutralized by adsorption with whole organisms and ultrasonically prepared extracts of gonococci. Adsorption of serum with fractions prepared from such extracts of gonococci could form the basis of a biological assay leading to the characterization of the antigens involved in antiserummediated loss of resistance to intracellular killing. As yet, there is no direct evidence that these antigens are the same as the aggressins conferring resistance to killing in the absence of antiserum. Antiserum might activate an alternative killing mechanism rather than block aggressin activity directly. However, the greater efficiency with which a strain with a high natural resistance to intracellular killing (BSDH) neutralized the action of antiserum compared to a strain with a low resistance (BSSH) suggests that there may be a correlation between aggressin activity and the number of antibody binding sites.

The results of adsorption with sonicates of the heterologous strain CSDH organisms are interesting with regard to a possible direct action of an aggressin in promoting resistance to intracellular killing. When this sonicate was present in the phagocytosis test, the effect of anti-BS serum on BSDH organisms was counteracted, but not when the gonococci were pretreated with the mixture of the antiserum and heterologous sonicate. Direct action of such sonicates on phagocytes could provide another assay for the possible aggressin and this is being investigated.

Further characterization of the factors involved in the resistance of gonococci to intracellular killing and the antiserum-mediated loss of such resistance would be valuable in 
understanding the pathogenesis of gonorrhoea and in the design of diagnostic tests and vaccines.

We thank Mrs P. Staley, Mrs J. Lichfield and our blood donors for their very valuable assistance.

\section{REFERENCES}

Bisno, A. L., OfeK, I., Beachey, E. H., Chandler, R. W. \& Curran, J. W. (1975). Human immunity to Neisseria gonorrhoeae: acquired serum opsonic antibodies. Journal of Laboratory and Clinical Medicine 86, 221-229.

Brooks, G. F., Israel, K. S. \& Petersen, B. H. (1976). Bactericidal and opsonic activity against Neisseria gonorrhoeae in sera from patients with disseminated gonococcal infection. Journal of Infectious Diseases 134, 450-462.

BuChanan, T. M. (1975). Antigenic heterogeneity of gonococcal pili. Journal of Experimental Medicine 141, 1470-1475.

Johnston, K. H., Holmes, K. K. \& Gotschlich, E. C. (1976). Serological classification of Neisseria gonorrhoeae. I. Isolation of outer membrane complex responsible for serotype specificity. Journal of Experimental Medicine 143, 741-758.

Novotny, P., Short, J. A. \& Walker, P. D. (1975). An electron microscope study of naturally occurring and cultured cells of Neisseria gonorrhoeae. Journal of Medical Microbiology 8, 413-427.

Novotny, P. \& TURNER, W. H. (1975). Immunological heterogeneity of pili of Neisseria gonorrhoeae. Journal of General Microbiology 89, 87-92.

OfEK, I., BEACHEY, E. H. \& Bisno, A. L. (1974). Resistance of Neisseria gonorrhoeae to phagocytosis: relationship to colonial morphology and surface pili. Journal of Infectious Diseases 129, 310-315.

Ovchinnikov, N. M. \& DelektorskiJ, V. V. (1977). Phagocytosis in the urethral discharge from patients with gonorrhoea. In Gonorrhoea: Epidemiology and Pathogenesis, FEMS Symposium no. 2, pp. 157-183. Edited by F. A. Skinner, P. D. Walker and H. Smith. London: Academic Press. Ovchinnikov, N. M., Delektorskis, V. V. \& DMITRIEv, G. A. (1976). Ultrastructure of gonococci in acute, chronic and asymptomatic gonorrhoea. British Journal of Venereal Diseases 52, 230-245.

Penn, C. W., Sen, D., Veale, D. R., Parsons, N. J., Smith, H. \& WiTT, K. (1976). Morphological, biological and antigenic properties of Neisseria gonorrhoeae adapted to growth in guinea-pig subcutaneous chambers. Journal of General Microbiology 97, 35-43.

Penn, C. W., Parsons, N. J., Sen, D., Veale, D. R. \& SмIтH, H. (1977a). Immunization of guinea pigs with Neisseria gonorrhoeae: strain specificity and mechanisms of immunity. Journal of General Microbiology 100, 159-166.

PenN, C. W., Veale, D. R. \& Smith, H. (1977b). Selection from gonococci grown in vitro of a colony type with some virulence properties of organisms adapted in vivo. Journal of General Microbiology 100, 147-158.

Penn, C. W., Parsons, N. J., Veale, D. R. \& Smith, H. (1978). Correlation with different immunotypes of gonococcal antigens associated with growth in vivo. Journal of General Microbiology 105, 153-157.

Punsalang, A. P., JR \& Sawyer, W. D. (1973). The role of pili in the virulence of Neisseria gonorrhoeae. Infection and Immunity 8, 255-263.

Veale, D. R., Smith, H., Witt, K. \& Marshall, R. B. (1975). Differential ability of colonial types of Neisseria gonorrhoeae to produce infection and an inflammatory response in subcutaneous perforated plastic chambers in guinea pigs and rabbits. Journal of Medical Microbiology 8, 325-335.

Veale, D. R., Finch, H., SMith, H. \& Witt, K. (1976). Penetration of penicillin into human phagocytes containing Neisseria gonorrhoeae: intracellular survival and growth at optimum concentrations of antibiotic. Journal of General Microbiology 95, 353-363.

Witt, K., Veale, D. R., Finch, H., Penn, C. W., SeN, D. \& SMITH, H. (1976a). Resistance of Neisseria gonorrhoeae grown in vivo to ingestion and digestion by phagocytes of human blood. Journal of General Microbiology 96, 341-350.

Witt, K., Veale, D. R. \& Smith, H. (1976b). Resistance to ingestion and digestion of Neisseria gonorrhoeae by phagocytes of human buffy coat. Journal of Medical Microbiology 9, 1-12. 